\title{
Swelling behaviour of isora/natural rubber composites in oils used in automobiles
}

\author{
LOVELY MATHEW ${ }^{\dagger}$, K U JOSEPH ${ }^{\ddagger}$ and RANI JOSEPH* \\ Department of Polymer Science and Rubber Technology, Cochin University of Science and Technology, \\ Kochi 682 022, India \\ ${ }^{\dagger}$ Department of Chemistry, Newman College, Thodupuzha 685 585, India \\ ${ }^{\star}$ Department of Chemistry, Federal Institute of Science and Technology, Angamaly 683 577, India
}

MS received 10 August 2005; revised 30 September 2005

\begin{abstract}
Natural rubber/isora fibre composites were cured at various temperatures. The solvent swelling characteristics of natural rubber composites containing both untreated and alkali treated fibres were investigated in aromatic and aliphatic solvents like toluene, and $\boldsymbol{n}$-hexane. The diffusion experiments were conducted by the sorption gravimetric method. The restrictions on elastomer swelling exerted by isora fibre as well as the anisotropy of swelling of the composite have been confirmed by this study. Composite cured at $100^{\circ} \mathrm{C}$ shows the lowest percentage swelling. The uptake of aromatic solvent is higher than that of aliphatic solvent for the composites cured at all temperatures. The effect of fibre loading on the swelling behaviour of the composite was also investigated in oils like petrol, diesel, lubricating oil etc. The \% swelling index and swelling coefficient of the composite were found to decrease with increase in fibre loading. This is due to the increased hindrance exerted by the fibres at higher fibre loadings and also due to the good fibre-rubber interactions. Maximum uptake of solvent was observed with petrol followed by diesel and then lubricating oil. The presence of bonding agent in the composites restrict the swelling considerably due to the strong interfacial adhesion. At a fixed fibre loading, the alkali treated fibre composite showed lower percentage swelling compared to the untreated one.
\end{abstract}

Keywords. Composites; equilibrium swelling; interfacial adhesion; isora fibre; bonding agent; reinforcement.

\section{Introduction}

Natural fibre reinforced composites is an emerging area in polymer technology. Strong environmental regulations and increased interest in the proper utilization of renewable natural resources have prompted the composite industry to develop ecofriendly components. Efforts have been made to find alternative reinforcements that are environmentally friendly while providing the same performance as their synthetic counterparts (Bledzki and Gassan 1999). With their low cost and high specific mechanical properties, natural fibres represent a good, renewable and biodegradable alternative to the most common synthetic reinforcement. However, in the development of their composites, the incompatibility of the fibres and poor resistance to moisture often reduce the potential of natural fibres. Experimental studies have shown that control of fibre matrix interfacial bond strength is a critical factor in obtaining the best mechanical properties out of the resultant composite material (Gassan et al 2000). Typically physical and chemical modifications of fibres and matrices have been performed in order to obtain closer surface properties of the compo-

*Author for correspondence (rani@cusat.ac.in) site constituents (Gonzales et al 1999; Bismarck et al 2000; Mohanty and Khan 2000; George et al 2001; Khalil et al 2001). A wide variety of natural fibres like coir, sisal, oil palm, banana, jute, pineapple, bamboo etc have been studied by several researchers in various polymers (Varghese et al 1991; Geethamma and Thomas 1995; Prasanth Kumar and Thomas 1995; Devi et al 1997; Ismail et al 1997; Pothen et al 1997; Chen et al 1998; Ansell and Mwaikambo 2002). In various cellulosic fibre elastomer composites, it was found that the aspect ratio of the fibre and its chemical treatment has a major role on composite properties. Rubber fibre composites are used in rubber industry due to the advantages they impart in processing and low cost coupled with high strength. Normally a rubber fibre composite can offer a set of properties that may give it the potential of entering application areas not possible with either of the components in the composite (Zan zig et al 1993). These composites combine the elastic behaviour of rubber with the strength and stiffness of fibre. The aim of the present work is to study the potential of using isora fibre as reinforcement in natural rubber. Isora is a bast fibre separated from the bark of Helicteres isora plant (figure 1) by retting process. Isora shrubs grow in many parts of South India, especially in Kerala. Isora resembles jute in appearance, with comparable strength, better durability and luster (see 
figure $1 \mathrm{~b})$. The properties of isora are found to be comparable to some other natural fibres. Recently in our laboratory, high performance cost effective composites have been developed by the incorporation of isora fibres into NR matrix (Lovely et al 2004a). Also we have reported about the possibilities of using isora fibre as a potential reinforcement in
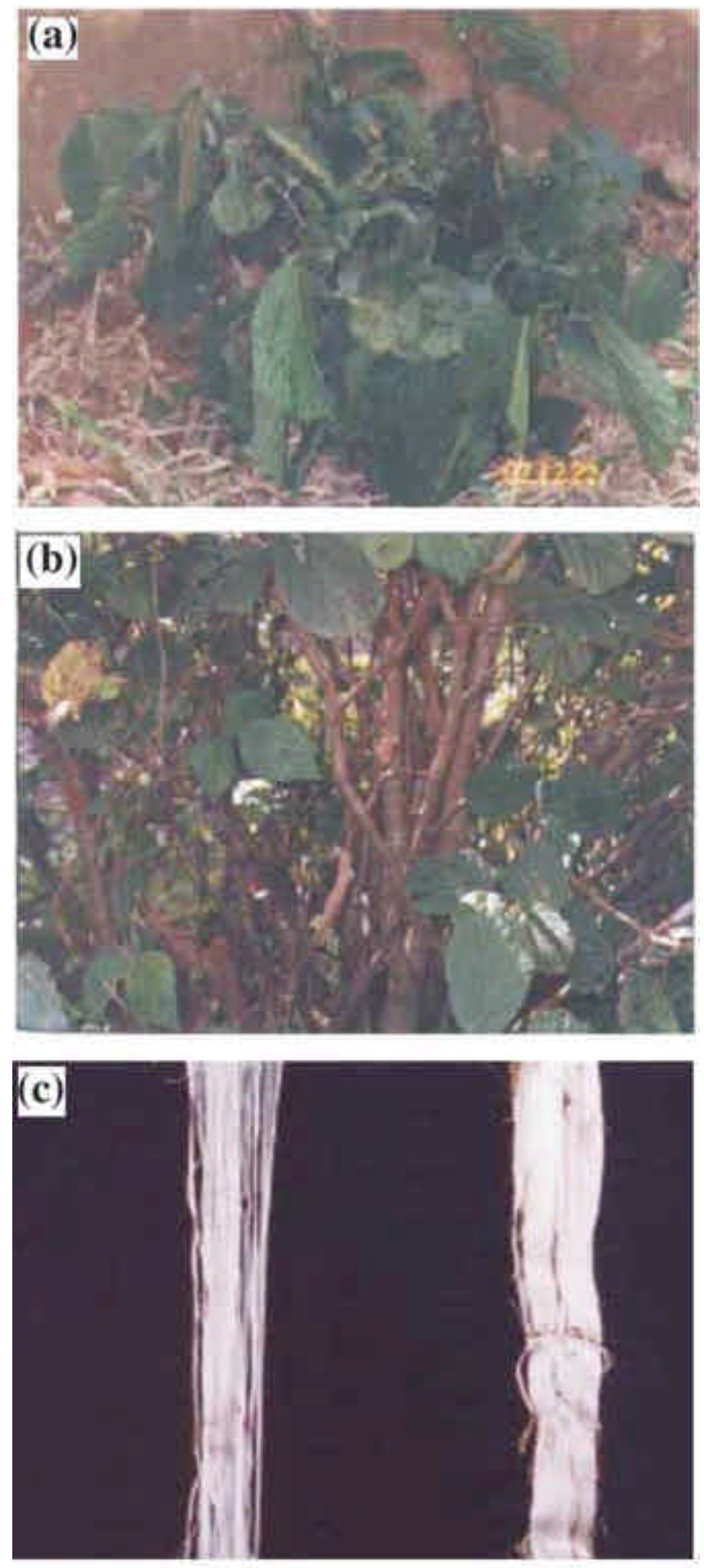

Figure 1. Helicteres isora plant: (a) small plant, (b) stem and (c) raw fibre. polyesters (Joshy et al 2005). The mechanical properties of these matrices are greatly improved by incorporation of this fibre. The resultant composite product will be a cost effective and value added material for various components of machines like conveyor belts, automobile parts etc. Effect of low temperature curing on the mechanical performance of these composites also have been investigated (Lovely et al 2004b). It has been observed that when compared to the usual curing systems of NR, the low temperature curing is more effective as evident from the mechanical properties. It is likely that at high temperature the fibre shows a tendency to undergo degradation. Solvent swelling experiments of rubbery composites are important as a method of analysing their service performance when in contact with solvents. Swelling of rubber vulcanizates in a number of solvents have been studied (Whity et al 1942; Gee 1943; Khinavar and Aminabhavi 1991). An important difference between vulcanized and raw rubber is that the former possesses a structure, which cannot be broken down completely by any solvent. The material, therefore, swells and cannot be dispersed. The contact of rubbers with organic solvents can be well explained by absorption and diffusion phenomena (Jost 1952). Numerous techniques like H-block and strip adhesion, both dynamic and static in nature, have been used to measure adhesion between fibre and rubber. While most of these techniques give a good relative indication of adhesion, the time dependent nature of the viscoelastic materials sometimes overshadows the real effect. Equilibrium swelling is another technique which has been used to assess the fibre/rubber adhesion. Fibres, if bonded effectively are supposed to restrict the swelling of elastomers. The adhesion between rubber and various synthetic fibres like glass, asbestos, and natural fibres like sisal, oil palm etc have been studied using restricted swelling measurements (Das 1973; Varghese et al 1995; Prasanth Kumar and Thomas 2001; Jacob et al 2004).

In this paper, we propose to study the swelling behaviour of short isora fibre reinforced natural rubber composites in oils used in automobiles. The effects of fibre loading, chemical modification of the fibre and presence of bonding agent on the swelling behaviour of these composites vulcanized at low and high temperatures are proposed to be investigated.

\section{Experimental}

\subsection{Materials}

The raw isora fibre used in the study was separated from the bark of the Helicteres isora plant by retting process. Then it was chopped to an average length between 9 and $11 \mathrm{~mm}$ and designated as untreated fibre. The properties of isora fibre in comparison with other natural fibres are given in table 1 . The NR used was supplied by RRII, Kottayam, Kerala. The solvents used were of reagent grade 
Table 1. Properties of isora and other natural fibres.

\begin{tabular}{lccccc}
\hline Fibre & Diameter $(\mu \mathrm{m})$ & $\begin{array}{c}\text { Micro fibrillar } \\
\text { angle (degrees) }\end{array}$ & $\begin{array}{c}\text { Cellulose/lignin } \\
\text { content }(\%)\end{array}$ & $\begin{array}{c}\text { Tensile } \\
\text { strength }(\mathrm{MPa})\end{array}$ & $\begin{array}{c}\text { Density } \\
\left(\mathrm{g} / \mathrm{cm}^{3}\right)\end{array}$ \\
\hline Isora & $10-20$ & $20-25$ & $75 / 23$ & $500-600$ & $1 \cdot 39$ \\
Coir & $100-460$ & $30-49$ & $43 / 45$ & $130-170$ & $1 \cdot 15$ \\
Sisal & $50-200$ & $10-22$ & $67 / 12$ & $400-600$ & $1 \cdot 45$ \\
Oil palm & $50-500$ & $40-46$ & $65 / 19$ & $200-250$ & $1 \cdot 45$ \\
Jute & $12-25$ & $8-10$ & $63 / 12$ & $430-530$ & $1 \cdot 45$ \\
Banana & $80-250$ & $10-15$ & $65 / 5$ & $500-700$ & $1 \cdot 35$ \\
\hline
\end{tabular}

Table 2. Compound formulation (phr).

\begin{tabular}{lcccccccccc}
\hline Ingredients & X10 & X20 & X30 & X40 & X10b & X20b & X30b & X40b & Y30 & Y30b \\
\hline RF resin & - & - & - & - & $2 \cdot 5$ & $5 \cdot 0$ & $7 \cdot 5$ & 10 & - & $7 \cdot 5$ \\
Silica & - & - & - & - & $1 \cdot 0$ & $2 \cdot 0$ & $3 \cdot 0$ & $4 \cdot 0$ & - & $3 \cdot 0$ \\
Hexa & - & - & - & - & $1 \cdot 6$ & $3 \cdot 2$ & $4 \cdot 8$ & $6 \cdot 4$ & $4 \cdot 8$ \\
Fibre [U] & 10 & 20 & 30 & 40 & 10 & 20 & 30 & 40 & 30 & 30 \\
Fibre [T] & - & - & - & - & - & - & - & - & - & 30 \\
\hline
\end{tabular}

Basic recipe: NR, 100; ZnO, 5.0; stearic acid, 2.0; TDQ, 1.0; S, 2.5. For low temperature curing system (ZDC, 1.0, Xanthate, 0.75). For conventional system (CBS, 0.6, TMTD, 0.1). [Conventionally cured composites are represented by $\mathrm{X}_{0}$, e.g. $\mathrm{X}_{0} 30 \mathrm{~b}, 30 \mathrm{phr}$ loading with bonding agent cured by conventional systems].

and were distilled before use. The automobile oils, the bonding agent [RF resin : hexa : silica] and all other ingredients used were of commercial grade.

\subsection{Chemical treatment of the fibre}

Untreated short fibres of an average length, $10 \mathrm{~mm}$, were immersed in $5 \%$ aqueous $\mathrm{NaOH}$ for $3-4 \mathrm{~h}$, then washed with water and dried in an air oven at $70^{\circ} \mathrm{C}$.

\subsection{Composite preparation}

Short isora fibres, both alkali treated and untreated, were incorporated into NR at different fibre loadings on a laboratory two-roll mill and vulcanized using conventional and low temperature curing accelerator systems based on the formulation given in table 2. Details of mixing and processing of these composites have been reported (Lovely et al 2004a).

\subsection{Sorption experiments}

Circular specimens of diameter, $20 \mathrm{~mm}$, were punched out from the vulcanized sheets. Thickness and diameter of the specimens were measured by means of a screw gauge and vernier calipers, respectively. Specimens of known weight were immersed in the solvents (toluene and hexane) and oils like petrol, diesel, lubricating oil etc in diffusion test bottles and kept at room temperature. Samples were removed from the bottles at periodic intervals and the wet surfaces were quickly dried using tissue paper and weights of the specimen after swelling were determined at regular intervals until no further increase in solvent uptake was detected. Thickness and diameter of the specimen after equilibrium swelling were also measured.

\subsection{Swelling data analysis}

2.5a Calculation of $Q_{t}$ (mol \% uptake of the solvent): The mol $\%$ uptake of the solvent, $Q_{\mathrm{t}}$, for the composite samples was determined using the equation

$$
Q_{\mathrm{t}}=\frac{\left(W_{2}-W_{1} / M_{\mathrm{s}}\right) \times 100}{W_{1}},
$$

where $W_{2}$ and $W_{1}$ are the weights of the specimen before and after swelling, and $M_{\mathrm{s}}$ the molar mass of the solvent.

2.5b Swelling parameters: Anisotropic swelling studies provided information on the interface strength, degree of dispersion of fibres and their alignment in the elastomer matrix. In order to assess the extent of swelling behaviour of composites, gum and fibre filled vulcanizates were swollen in solvents and oils under study and the swelling parameters like swelling index, swelling coefficient were evaluated.

2.5b (i) Swelling index: Swelling index is calculated by the equation

$$
\text { Swelling index } \%=\left(W_{2}-W_{1}\right) / W_{1} \times 100,
$$

where $W_{1}$ and $W_{2}$ are the initial and final (swollen) weights of the sample. 
2.5b (ii) Swelling coefficient: The swelling behaviour of the composites can also be analysed from the swelling coefficient values (table 2). It is an index of the ability with which the sample swells and is determined by the equation

$$
\text { Swelling coefficient, } \alpha=\left\{A_{\mathrm{s}} / m\right\} \times[1 / d],
$$

where $A_{\mathrm{s}}$ is the weight of the solvent sorbed at equilibrium swelling, $m$ the mass of the sample before swelling and $d$ the density of the solvent used.

2.5b (iii) Rubber-fibre interactions: The extent of interaction between rubber and fibre can be analysed using Kraus equation which is given by

$$
V_{\mathrm{ro}} / V_{\mathrm{rf}}=1-m[f / 1-f],
$$

where $V_{\text {ro }}$ and $V_{\text {rf }}$ are the volume fractions of rubber in the gum vulcanizate and in fibre filled swollen sample, respectively, $f$ the volume fraction of fibre and $m$ the fibre polymer interaction parameter.

$2.5 \mathrm{~b}$ (iv) Volume fraction of rubber in the swollen sample $\left(V_{r f}\right)$ : The volume fraction of rubber in the swollen sample $V_{\text {rf }}$, was calculated by the expression

$$
V_{\mathrm{rf}}=\frac{\left[(D-F T) /\left(d_{\mathrm{r}}\right)\right]}{\left[(D-F T) /\left(d_{\mathrm{r}}\right)\right]+\left[A_{0} / d_{\mathrm{s}}\right]},
$$

where $d_{\mathrm{r}}$ and $d_{\mathrm{s}}$ are the densities of the rubber and solvent, $D$ the deswollen weight of the test specimen (dry weight), $F$ the weight fraction of the insoluble components, $T$ the weight of the specimen and $A_{0}$ the weight of the absorbed solvent corrected for swelling increment, respectively.

2.5c Optical and SEM studies: The physical nature of the composite samples before and after sorption studies was analysed using an optical microscope. Treated and un- treated fibre surfaces were examined by scanning electron microscopy [SEM].

\section{Results and discussion}

\subsection{Effect of curing temperature}

Figures $2 \mathrm{a}$ and $\mathrm{b}$ show the variation of the mol\% uptake of toluene and hexane with curing temperature of the composites. In both solvents the uptake of solvent is lowest for the composite vulcanized at $100^{\circ} \mathrm{C}$. The same trend is observed in the case of composites containing treated fibres and with bonding agent. A comparison of the mol\% uptake of the solvent for the composites cured at $100^{\circ} \mathrm{C}$ and $150^{\circ} \mathrm{C}$ in toluene and hexane are given in figures $3 \mathrm{a}$ and $\mathrm{b}$. It may be observed that the uptake of solvent is high for the composite cured at high temperature $\left(150^{\circ} \mathrm{C}\right)$ for a particular fibre loading ( $30 \mathrm{phr}$ ). This shows that the reinforcement is most effective when the composite is cured at $100^{\circ} \mathrm{C}$ and it is likely that at high temperature the fibre and rubber show a tendency to degrade as evident from the results of our previous studies (Lovely et al 2004b).

\subsection{Effect of fibre loading and bonding agent}

The diffusion mechanism in rubbers is essentially connected with the ability of the polymer to provide pathways for the solvent to progress in the form of randomly generated voids. As the void formation decreases with fibre loading, the solvent uptake also decreases. The ratio, $V_{\mathrm{ro}} / V_{\mathrm{rf}}$, represents the degree of restriction of the swelling of rubber matrix due to the presence of fibre. From the table it is observed that as fibre loading increases the solvent uptake of the sample decreases which causes an increase in $V_{\text {rf }}$, which will decrease the ratio, $V_{\text {ro }} / V_{\text {rf }}$, since $V_{\text {ro }}$ is a constant. According to Kraus theory and Kraus equation (Kraus 1965), the
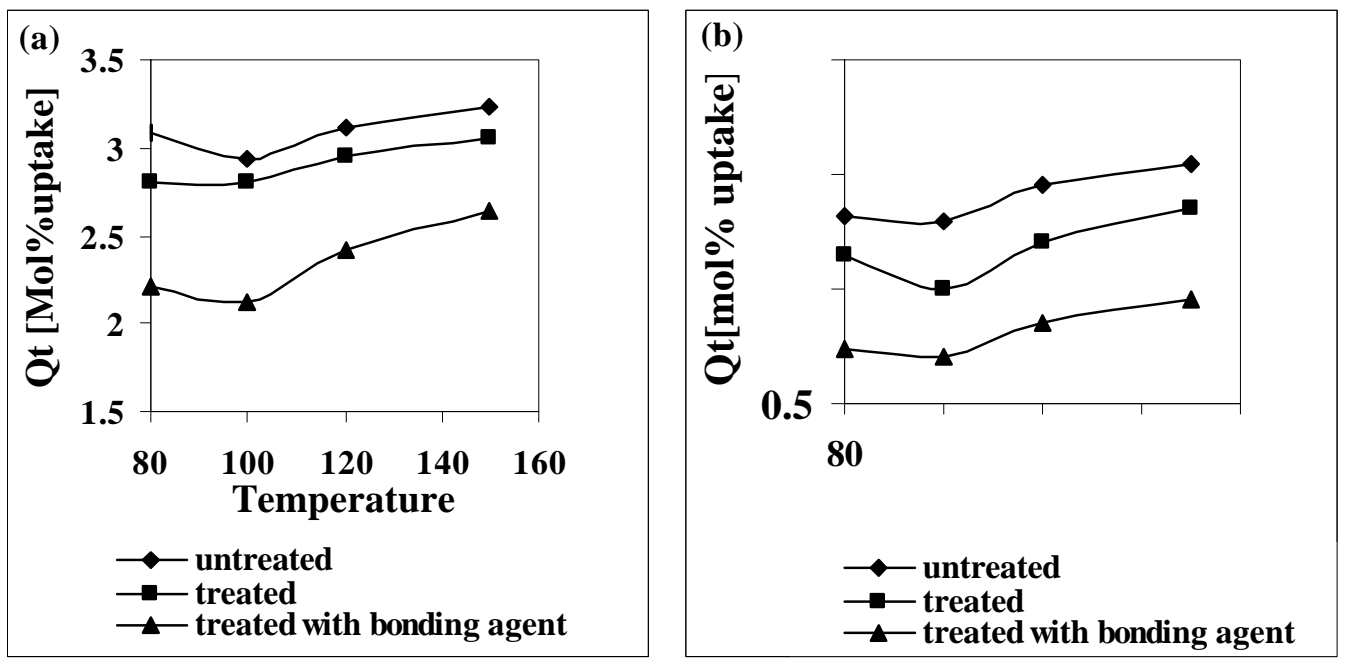

Figure 2. Variation of mol\% uptake of solvent with curing temperature of the composites in (a) toluene and (b) $n$-hexane. 

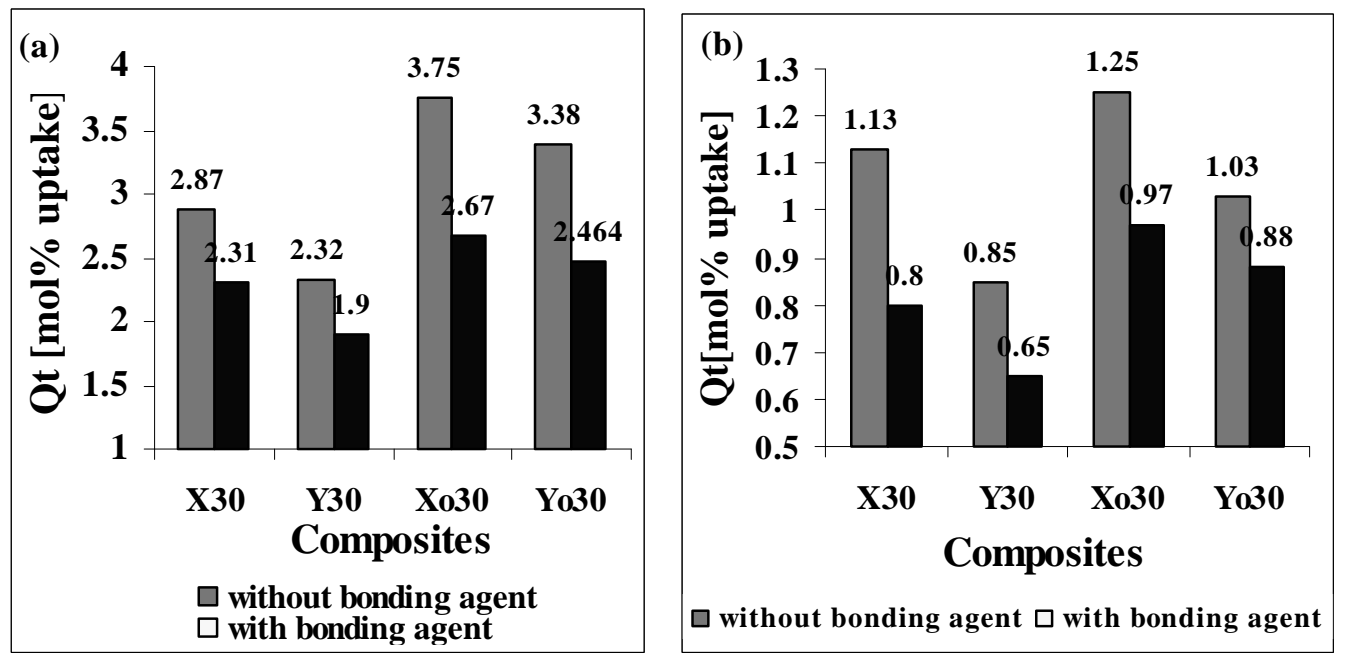

(Mixes defined in Table 2)

Figure 3. A comparison of the mol\% uptake of the solvent for the composites (30 phr) cured at $100^{\circ} \mathrm{C}$ and $150^{\circ} \mathrm{C}$ in (a) toluene and (b) $n$-hexane.
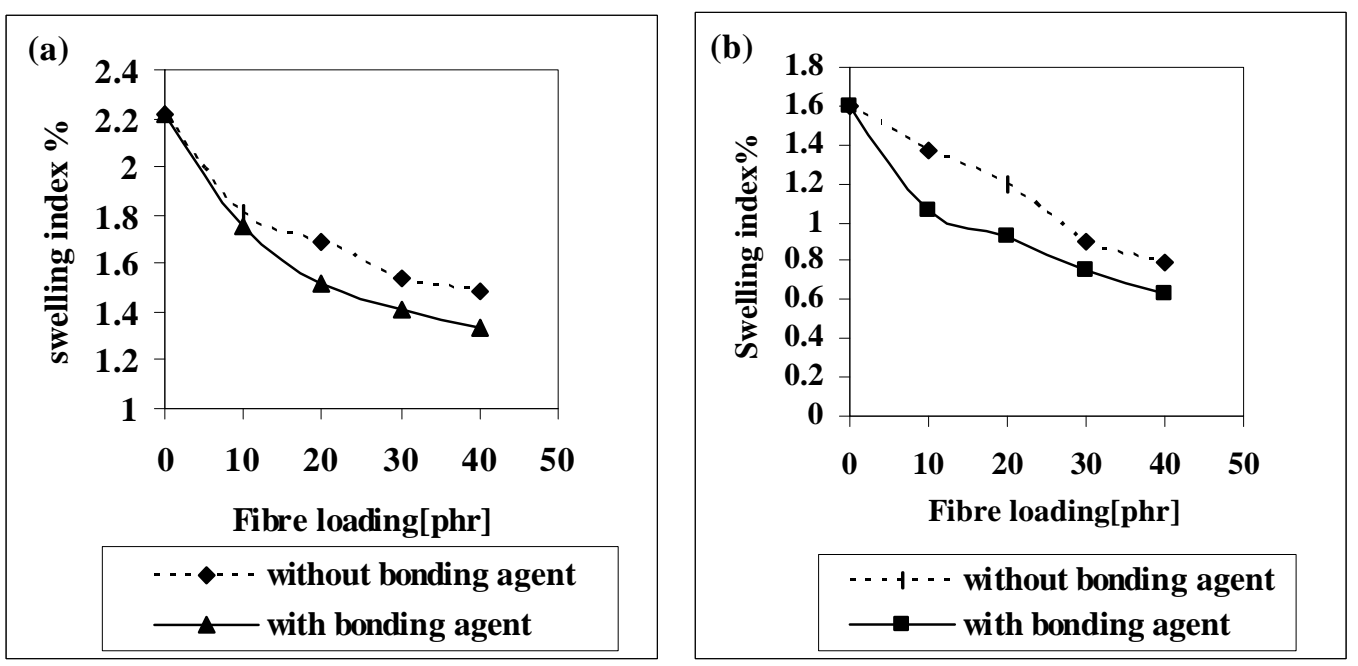

Figure 4. Variation of the $\%$ swelling index with fibre loading for the composites cured at $100^{\circ} \mathrm{C}$ in (a) petrol and (b) diesel.

reinforcing fillers will have a negative higher slope. The decreased $V_{\text {ro }} / V_{\text {rf }}$ values at higher loadings indicate the reinforcement effect of the fibres. Further reduced $V_{\mathrm{ro}} / V_{\mathrm{rf}}$ values of the bonded samples are associated with the enhanced fibre-rubber adhesion. Figures $4 \mathrm{a}$ and $\mathrm{b}$ give the variation of $\%$ swelling index with fibre loading for the composites cured at low temperature $\left(100^{\circ} \mathrm{C}\right)$ in automobile oils like petrol and diesel. It is clear that as fibre loading increases, equilibrium solvent uptake decreases. This is obviously due to the increased hindrance exerted by the fibres at higher loadings. It has already been established that for cellulose fibre and natural rubber, bonding agents like hexa-resorcinol-hydrated silica (HRH) system can be used which involves a condensation reaction between the methylol groups of resorcinol which in turn reacts with unsaturation in the polymer chain resulting in a covalent linkage between fibre, rubber and resin (Blackley 1997). Since there is a better bonding between fibre and rubber, a strong interface is developed, which restricts the entry of the solvent. It is observed that in composites containing bonding agent there is a sharp decrease in the uptake of solvents. A highly bonded system would exhibit high resistance to swelling compared to the unbonded systems (Varghese $e t$ al 1995). The effect of fibre loading and bonding agent on the swelling index of the composites in lubricating oil at different temperatures is given in figure 5. Here also as fibre loading increases the oil uptake decreases. At room temperature the composites show greater resistance to swelling. As temperature increases the uptake of oil increases. At higher temperature the viscosity of the oil decreases, 
the molecules are free to move and can very well penetrate into the composite. The presence of bonding agent in the composites restricts the swelling considerably due to the strong interfacial adhesion. Maximum uptake of solvent was observed with petrol followed by diesel and then lubricating oil. The low molecular weight hydrocarbons present in petrol can easily penetrate into the material. As the molecular size increases as in diesel and lubricating oil, the uptake of oil decreases. This may be due to the larger size of solvent molecule that hinders the molecule from entering into the voids or solvent pockets present in the composite. Solomon and Amerongen (1948) reported that the liquid uptake increases as the molecular size increases and reaches a maximum value and then decreases. The swelling coefficient of the mixes in various oils is given in table 3 . It is clear that mixes with bonding agent have comparatively low values than the unbonded ones, which is due to the improved interfacial bonding between fibre and rubber.

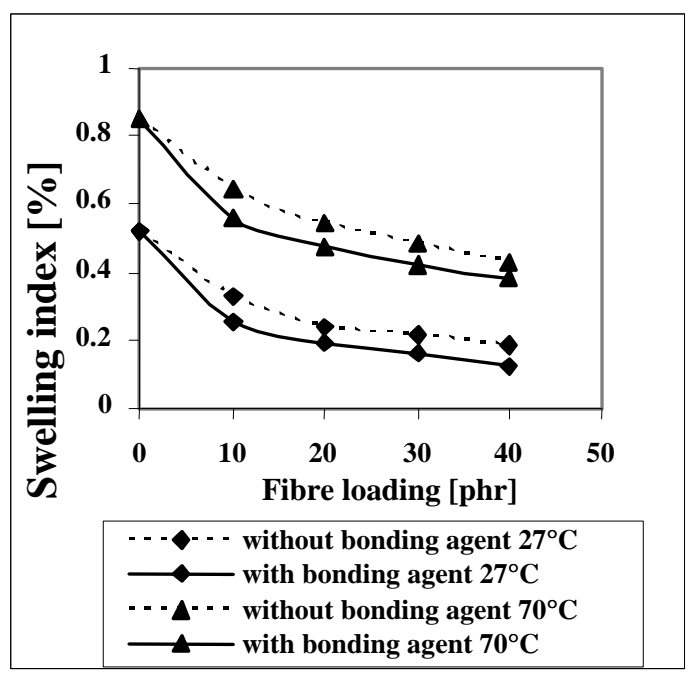

Figure 5. Variation of the $\%$ swelling index with fibre loading for the composites cured at $100^{\circ} \mathrm{C}$ in lubricating oil at $27^{\circ} \mathrm{C}$ and $70^{\circ} \mathrm{C}$.

Table 3. Swelling coefficient of the mixes in various oils.

\begin{tabular}{|c|c|c|c|}
\hline Mixes & Petrol & Diesel & Lubricating oil \\
\hline Gum & $3 \cdot 46$ & 1.93 & $0 \cdot 808$ \\
\hline X10 & $2 \cdot 71$ & $1 \cdot 65$ & 0.626 \\
\hline X10b & $2 \cdot 57$ & $1 \cdot 28$ & $0 \cdot 561$ \\
\hline X20 & $2 \cdot 58$ & $1 \cdot 35$ & $0 \cdot 540$ \\
\hline X20b & $2 \cdot 32$ & $1 \cdot 11$ & $0 \cdot 423$ \\
\hline $\mathrm{X} 30$ & $2 \cdot 42$ & 1.09 & 0.451 \\
\hline $\mathrm{X} 30 \mathrm{~b}$ & $2 \cdot 31$ & $1 \cdot 02$ & $0 \cdot 387$ \\
\hline $\mathrm{X} 40$ & $2 \cdot 41$ & $0 \cdot 96$ & $0 \cdot 41$ \\
\hline $\mathrm{X} 40 \mathrm{~b}$ & 1.91 & $0 \cdot 88$ & $0 \cdot 369$ \\
\hline Y30 & $2 \cdot 12$ & $1 \cdot 01$ & $0 \cdot 411$ \\
\hline Y30b & 1.95 & $0 \cdot 90$ & $0 \cdot 379$ \\
\hline
\end{tabular}

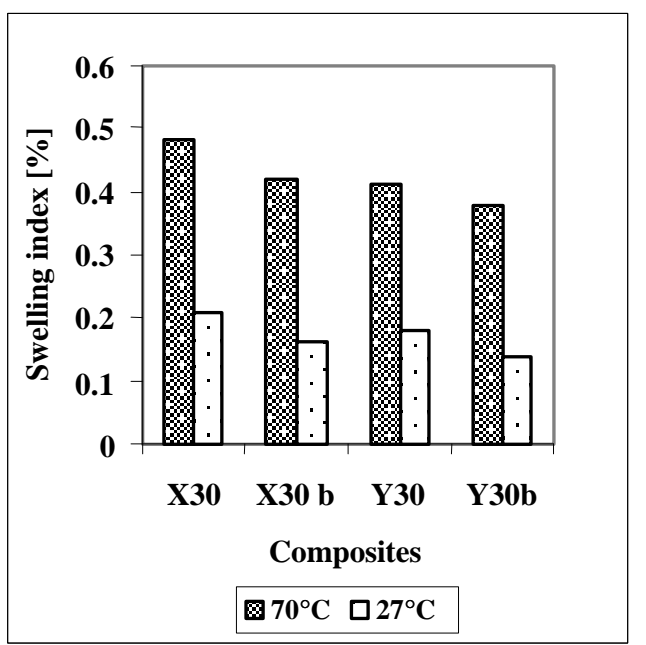

Figure 6. A comparison of the $\%$ swelling index for the composite $(30 \mathrm{phr})$ containing untreated and alkali treated fibres in lubricating oil at $27^{\circ} \mathrm{C}$ and $70^{\circ} \mathrm{C}$.
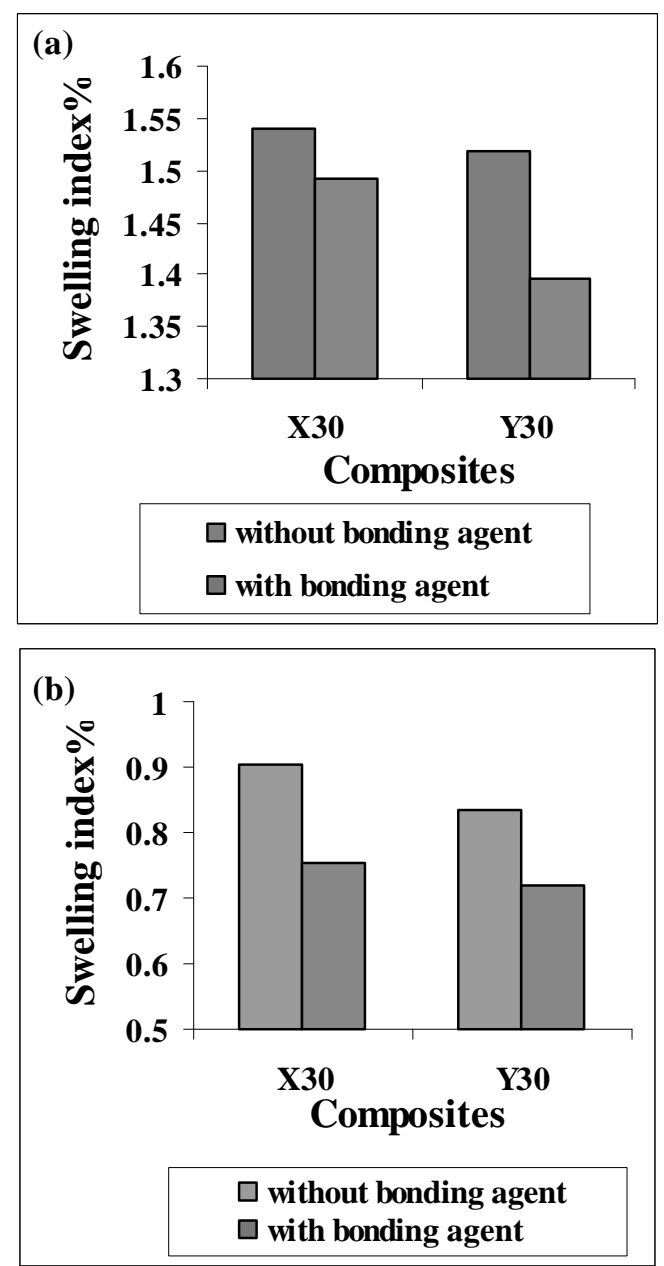

(Mixes defined in Table 2)

Figure 7. A comparison of the \% swelling index for the composite $(30 \mathrm{phr})$ containing untreated and alkali treated fibres in (a) petrol and (b) diesel. 

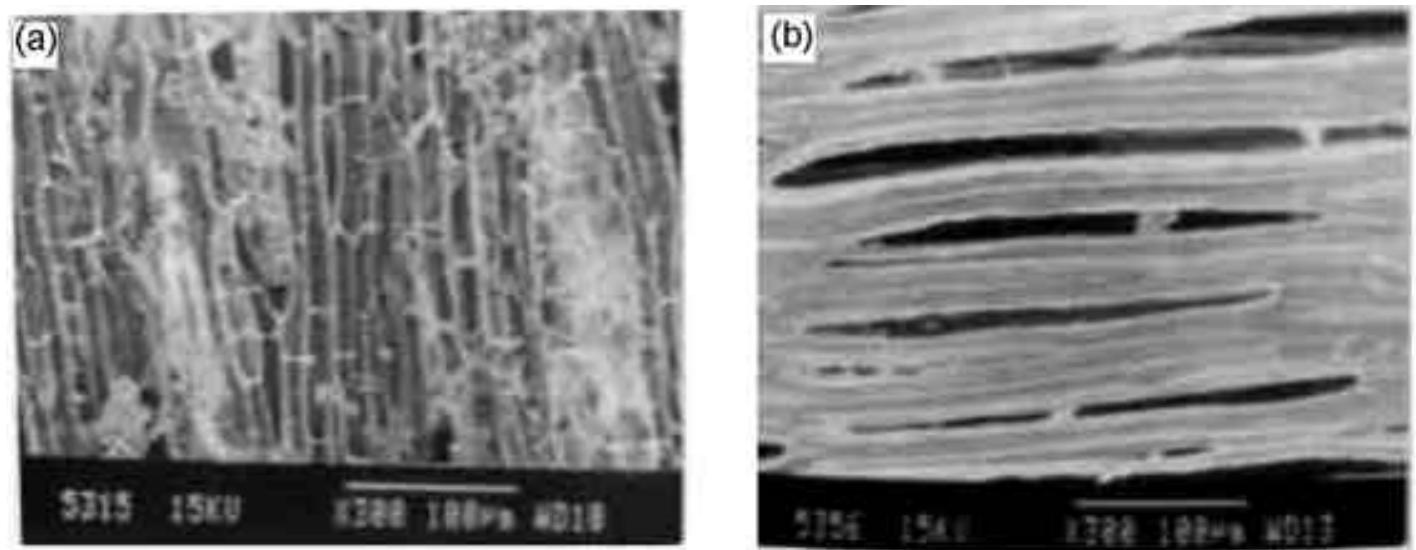

Figure 8. SEM photographs of (a) untreated and (b) alkali treated fibres $(\times 300)$.
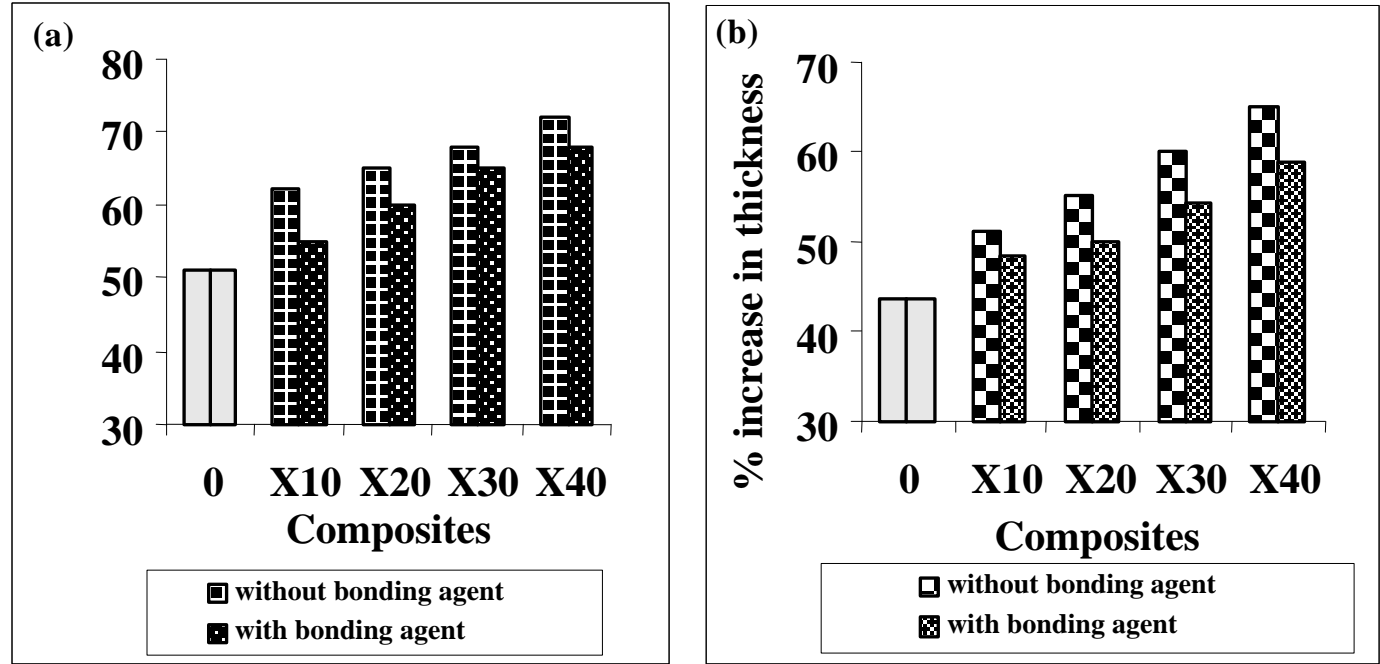

(Mixes defined in Table 2)

Figure 9. Variation of $\%$ increase in thickness with fibre loading for the composite cured at $100^{\circ} \mathrm{C}$ in $(\mathbf{a})$ petrol and (b) diesel.

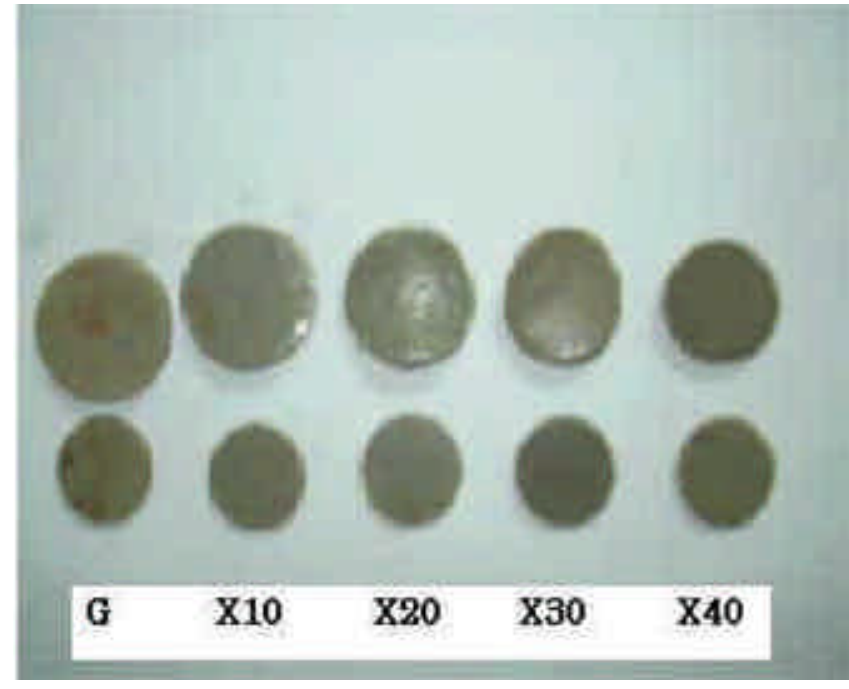

Figure 10. Optical photograph of the samples of varying fibre loadings before and after swelling in petrol (Mixes defined in table 2).

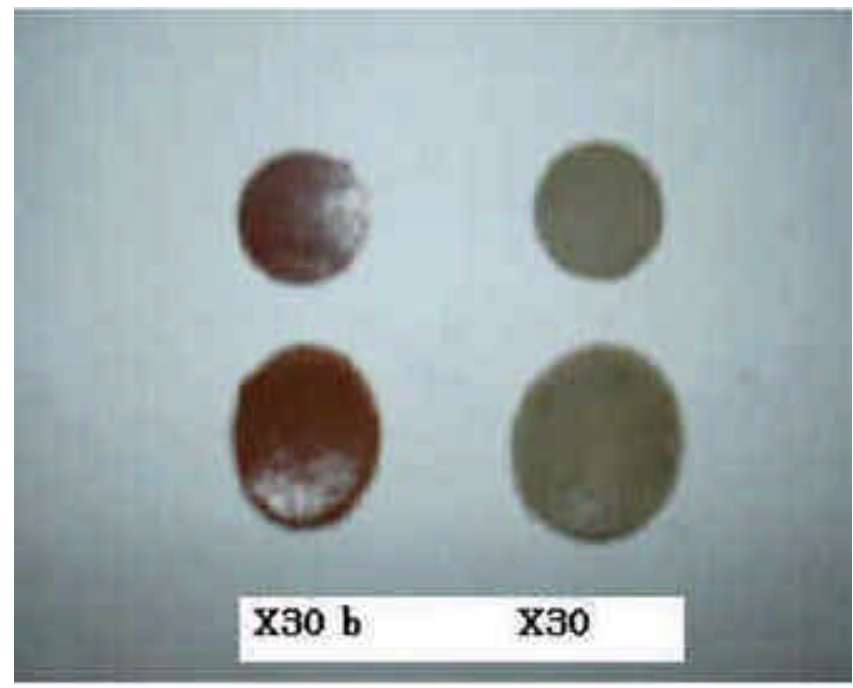

Figure 11. Optical photograph of the samples with and without bonding agent before and after swelling in petrol (Mixes defined in table 2). 
Table 4. $V_{\text {rf }}$ and $V_{0} / V_{\text {rf }}$ values of the mixes in petrol.

\begin{tabular}{lcl}
\hline Mixes & $V_{\mathrm{rf}}$ & $V_{0} / V_{\mathrm{rf}}$ \\
\hline X10 & 0.1926 & 0.653 \\
X10b & 0.2325 & 0.5415 \\
X20 & 0.2360 & 0.5334 \\
X20b & 0.2414 & 0.5215 \\
X30 & 0.2196 & 0.5733 \\
X30b & 0.2430 & 0.5181 \\
X40 & 0.2542 & 0.4952 \\
X40b & 0.2584 & 0.4872 \\
\hline
\end{tabular}

\subsection{Effect of chemical treatment}

The effect of chemical treatment of fibres on equilibrium swelling of the composites in various oils can also be evident from figures 6 and 7. It is observed that in composites containing treated fibre, the solvent uptake is reduced further, which is due to the enhanced interfacial bonding between the fibre and rubber. This prevents the transport of solvent to some extent through the interface. The surface topology of the untreated fibre is shown in figure $8 \mathrm{a}$. The fibrillar nature as well as the porosity of the fibre is revealed from the fibre topography. The porous surface morphology is useful to have better mechanical interlocking in the matrix for composite fabrication. Fibre shows an uneven surface due to protrusions constituted of hemi cellulose and pectin. The surface contains a waxy cuticle layer also, which prevents a better interlocking with the rubber. On alkali treatment the pores become clearer and fibres become thinner than raw fibre as shown in figure $8 \mathrm{~b}$. This may be due to the dissolution and leaching out of fatty acids and lignin components of the fibre. This renders roughness to the fibre thereby enhancing the mechanical interlocking at the interface. Thus it is clear that equilibrium liquid uptake can provide information regarding the efficiency of interfacial bonding. On comparing the solvent uptake of composites containing chemically modified fibres with that of untreated ones it can be seen that the former composites are better than the latter in resisting the uptake of solvents/oils as evident from figures 6 and 7.

\subsection{Dimensional changes of composites}

The percentage increase in thickness at equilibrium swelling for the composites cured at $100^{\circ} \mathrm{C}$ in petrol and diesel are shown in figures $9 \mathrm{a}$ and $\mathrm{b}$. It is observed that the change in thickness is higher for the composite without bonding agent and it increases marginally with fibre loading. In an oriented fibre-rubber composite, the swelling is anisotropic. The oriented fibres will prevent the penetration of the liquid in the direction perpendicular to the flat surfaces of the specimen. The solvent can diffuse into the polymer mostly through a direction parallel to fibre orientation. At low fibre loadings, the penetrant can enter into the matrix both in the direction parallel and perpendicular to the fibre orientation. The matrix, therefore, swells both in diameter and thickness directions. As a result at low loading, the net swelling taking place in the thickness direction will be less. As fibre loading increases, the number of fibres in a unit volume increases and the penetrant molecule finds it difficult to diffuse into the polymer and therefore, the swelling takes place mostly in the thickness direction. Thus at higher loadings swelling was found to be constrained in one direction and as a result the thickness of the specimen increased considerably. Although during swelling dimensional changes are shown by both bonded and unbonded composites, the effect is more pronounced in the case of composite without bonding agent. Due to the strong interfacial adhesion between fibre and rubber, for the bonded composites the dimensional changes after swelling are less when compared to the unbonded composites. In diesel the percentage increase in thickness is less when compared to that of petrol.

Optical photographs of samples cured at $100^{\circ} \mathrm{C}$ for varying fibre loadings before and after swelling in petrol are shown in figure 10. From the figure it is clear that as fibre loading increases the diameter of the swollen samples decreases. At the same fibre loading ( $30 \mathrm{phr})$ the diameter of the bonded composite is lower than that of the unbonded composite as is evident from figure 11. From this it is evident that in unbonded composites swelling occurs predominantly in the thickness direction. Thus the restricted equilibrium swelling can be used to measure the extent of interfacial bonding between fibre and rubber.

\section{Conclusions}

Equilibrium swelling observed in isora fibre reinforced natural rubber is lower for the composite cured at $100^{\circ} \mathrm{C}$ than that cured at $150^{\circ} \mathrm{C}$ in solvents like toluene and hexane. The uptake of aromatic solvent is higher than aliphatic solvent for the composites. Maximum uptake was observed with petrol followed by diesel and then lubricating oil. Increased fibre content brings about greater restriction to swelling, and the \% swelling index and swelling coefficient are substantially lower for the composites with bonding agent.

Composites containing alkali treated fibre absorbed less solvent compared to those with untreated fibre indicating that alkali treatment improves the adhesion between fibre and rubber. At higher fibre loadings swelling predominantly takes place in the thickness direction.

\section{References}

Ansell M and Mwaikambo L Y 2002 J. Appl. Polym. Sci. 84 2222

Blackley D C 1997 Polymer lattices (London: Chapman and Hall) II edn, Vol. 3, p. 517 
Bledzki A K and Gassan J 1999 Prog. Polym. Sci. 24221

Bledzki A K, Reihmane S and Gassan J 1996 J. Appl. Polym. Sci. 591329

Bismarck A, Mohanty A K and Khan M A 2000 Colloid. Polym. Sci. 27829

Chen X, Guo Q and Mi Y 1998 J. Appl. Polym. Sci. 691891

Das B 1973 J. Appl. Polym. Sci. 171019

Devi L, Bhagawan S and Thomas S 1997 J. Appl. Polym. Sci. 641739

Gassan J, Gutowski V S and Bledzki A K 2000 Macromol. Mater. Eng. 283132

Gee G 1943 Rubb. Chem. Technol. 16263

George J, Sreekala M S and Thomas S 2001 Polym. Eng. Sci. 411471

Geethamma V G and Thomas S 1995 J. Appl. Polym. Sci. 55583

Gonzales A V, Olayo R and Franco H 1999 Composites Part B 30309

Ismail H, Rozman H D and Ishiaku U S 1997 Polym. Int. 43223

Jacob M, Thomas S and Varghese K T 2004 Comp. Sci. Technol. 64955

Joshy M K, Lovely M and Rani J 2005 Proceedings of the first international conference ICBC 2005 (Kerala: M G University) p. 113

Jost W 1952 Diffusion in solids, liquids and gases (New York: Academic Press)

Khalil H P, Ismail H and Rozman H D 2001 Eur. Polym. J. 371037
Kraus C 1965 Rubb. Chem. Technol. 381070

Khinavar K S and Aminabhavi T M 1991 J. Appl. Polym. Sci. 42 2321

Lovely M, Joseph K U and Rani J 2004a Prog. Rubb. Plast. Recyl. Technol. 20337

Lovely M, Shiny P and Rani J 2004b Proceedings of the international conference on polymers for advanced technologies, Macro 2004 (Trivandrum: Society of Polymer Scientist India)

Mohanty A K and Khan M A 2000 Composites Part A 31 143

Prasanth Kumar R and Thomas S 1995 Bull. Mater. Sci. 181021

Prasanth Kumar R and Thomas S 2001 J. Adhesion Sci. Technol. 15633

Pothen L, Neelakandan N R and Thomas S 1997 J. Reinf. Plast. Comp. 16744

Solomon G and Amerongen G J V 1948 Rubb. Chem. Technol. 2167

Varghese S, Kuriakose B and Thomas S 1991 Ind. J. Nat. Rubb. Res. 455

Varghese S, Kuriakose B and Thomas S 1995 Rubb. Chem. Technol. 6837

Whity J, Evans S and Pasternack B 1942 Trans. Faraday Soc. 38269

Zan zig D J, Magnus F L and Halasa A F 1993 Rubb. Chem. Technol. 66456 